\title{
Note from the Editor-in-Chief
}

The world has changed dramatically in 2020 , and in ways that are directly relevant to our field. While the SARS-CoV-2 outbreak has developed into a global pandemic, healthcare structures and systems have been pushed to the breaking point in many parts of the world. As these events have unfolded, a sizeable segment of patients, practitioners, scientists, and health policy authorities worldwide have looked to traditional Asian medicine as a potential source of knowledge for how to treat or prevent infection. Among different communities, such efforts have included research into the antiviral properties of specific traditional medicines, specialized herbal formulas customized for covid-19, novel ritual interventions to protect against disease, and other therapeutic protocols that draw from Asia's rich traditions of healing. As scholars, many of us are tracking these developments, as well as investigating the wide range of other ways that the pandemic is affecting healthcare on the ground. We are doing so even while we ourselves, our loved ones, and our own communities are being affected by the pandemic in so many difficult ways.

As the historians among us will know well, social and political unrest are inevitable in times of epidemics. This is perhaps doubly true in the current pandemic, which has caused a major global economic slowdown and exacerbated socioeconomic inequalities around the world. In the United States, in particular, the brunt of both the medical and economic suffering has to date fallen disproportionally on non-white communities in poorer urban centers. When on May 25 of this year, four police officers in the city of Minneapolis callously murdered a 46-year old African American man named George Floyd, communities of color and their allies all over the country took to the streets to protest police brutality, lack of police accountability, and systemic racial discrimination in the U.S. Shared widely on social media, video footage of the murder and the consequent protests have inflamed pre-existing tensions that have racked the American political system since 2016. Both in the U.S. and beyond, this entire series of events has brought the issue of racism to the forefront of many of our minds. They also have challenged us to examine how our own scholarly practices have contributed to systemic racism in our own field of Asian medicine. 
As every one of our readers knows well, scholarly and editorial work takes time, and an academic journal such as this one will naturally lag behind fastbreaking developments such as these. This should by no means be taken as a lack of interest or engagement with these issues on the part of the editorial team. Indeed, our entire team has leaped into action to engage with both the pandemic and systemic racism in a direct and meaningful way. The current issue represents work that was in our pipeline in 2019, but we are working hard to ensure that upcoming issues will focus on the critically important issues affecting our lives in 2020 .

On behalf of the entire Asian Medicine editorial team, I wish all of our readers health, safety, and strength in these difficult times.

\section{Pierce Salguero}

August, $202 \mathrm{O}$ 